\title{
A survey on occupational accidents among construction industry workers in Yazd city: Applying Time Series 2006- 2011
}

\author{
Halvani GH, MSc ${ }^{1}$, Jafarinodoushan R, MSc ${ }^{2 *}$, Mirmohammadi SJ, MD ${ }^{3}$, Mehrparvar AH, MD ${ }^{3}$ \\ 1. Faculty member, Dept. of Occupational Health, School of Public Health, Shaheed Sadoughi University of Medical \\ Sciences, Yazd, Iran. 2. Faculty member, Occupational Health Research Center, Shaheed Sadoughi University of \\ Medical Sciences, Yazd, Iran. 3. Assistant prof., Occupational Health Research Center, Shaheed Sadoughi University of \\ Medical Sciences, Yazd, Iran.
}

Abstract:

Received: September 2011, Accepted: October 2011

Background: Millions of construction industry accidents occur in the world causing demages and injuries to workers and consequently economical losses every year. The aim of this study was to determine an estimator model for accidents among construction industry workers, in the years 2006 - 2011 for the first time, in Yazd city.

Materials and Methods: In this descriptive study, the questionnaire included items asking about variables such as age, occupation, type of accident, injured organ and the outcome of the accident. Time Series Model was used in this study to estimate accidents among the Yazd construction workers up to 2011.

Results: Fatality rate of workers who did not have insurance was more than those who had, which was statistically significant $(\mathrm{p}<0.001)$. The greatest rate of accident was falling $(48.58 \%)$ and the lowest was chocking (29\%). The relationships of accident outcomes with type of occupation and also the injured part of body were statistically significant in the construction industry $(\mathrm{p}<0.001)$. After testing many models, time series model of quadratic form was the closest model to the trend of data.

Conclusions: This model estimation shows that if the situation is the same as now in 2011 the accident cases will be more than 300 per year in 2012 and later. So this model is recommended to make changes in the trend for preventing the accidents in the future.

Keywords: Accidents, Time Series Analysis, Construction Workers, Yazd City.

\section{Introduction}

Eventhough modern life has brought more comfort and convenience for the communities, it has also caused hazards and accidents in human life. Millions of occupational accidents occurring annually impose damages and economical losses to societies [1]. Accidents have been rendered as one of the most important crippling factors contributing to disabilities and lifethreatening situations in the developed and developing countries [2]. An accident is defined as an inadvertent happening occasionally being damaging and detrimental which prevents the normal continuation, progress, or performance of a task or activity. It is most often induced by unsafe acts or conditions or a combination of the two. The occurrence of numerous catastrophic events in recent decades have demonstrated that the consequences resulting

corresponding author: Reza Jafarinodoushan, Occupational Health Research Center, Shaheed Sadoughi University of Medical Sciences, Yazd, Iran. E-mail : Jafarinodoushan@gmail.com 
from ignorance of safety principles and reaching of unwanted energies to damageable or fragile elements and materials can lead to a threat towards the human's economical, social, and political elements [3].

Also, occupational accidents exert a considerable effect on the public health. A study revealed that about 120 million accidents occurred in 1993 leading to 210000 deaths (500 deaths per day) at their workplace. Studies in the following years also demonstrated that this number was increased in 1994 afterwards. Furthermore, 17 million working days were lost in England due to accidents in 1997 [4]. In our country, high amounts of money are annually devoted to compensating for payments of illness bouts of employees when they are off work or for work place disability payments. This imposes many damages to the active manpower of our society [1]. The building industry is one of the most hazardous fields around the world [5]. Building activities is considered as one of the most dangerous jobs in Hong Kong. The occurrence of various building accidents is one of the leading causes of mortality and morbidity in this country [6,7]. In addition to job related accidents, the building workers are faced with pathogens as asbestos, sillies, fumes, noise pollution, and other endangering factors in their work milieu. Yet, most of these workers live in poor hygienic conditions and inappropriate conveniences $[8,9]$. The age range curve shows that the age group of 20-29 years have suffered from most damages.

Another study carried out in Rafsanjan in south East of Iran on construction workers showed that most of the injured workers were employed in the welding section, and had a work experience of less than five years. The causes of accidents were mostly carelessness and lack of the use of safety appliances [10].
A study by Halvani reported the accidents to be the most among the workers with less than one year of experience and the least among the workers with more than 20 years of experience [11]. In the study by Colak, carelessness and lack of use of a suitable protection accounted for the first and second cause of occurrence of accidents, respectively [12]. Many research projects have been carried out on the occupational accidents in which factors contributing to the accidents have been determined. Among these factors are: type of accident [13-17], cause of damage [15,18-21], source of accident [11,22], month of accident [16], worker's experience $[12,18]$ and worker's age $[12,13,16,23]$. The present study applied all these factors in the Time Series Model to estimate the related variables. Due to the fact that $\% 9-12$ of the workers in our country are busy in this section and few epidemiological studies have been carried out on this subject, the present study made an attempt to manage the building accidents process efficiently via studying the population as well as some factors such as time of accident, cause of accident, and consequences of accidents. Since estimating the distribution of accidents and determining their model of occurrence are effective factors for planning and prevention of accidents in future, this study used the Time Series Model for the first time to study accidents. The purpose of this research was to determine a predictor model for accidents of construction industry until 2011, for the first time, in Yazd city.

\section{Materials and Methods}

This was a descriptive modeling study in which all the construction workers sustaining occupational accidents during 2002-2006 were included. Information about accidents was recorded in the Office for Work and 
Social Affairs in Yazd. The population under study included 247 construction workers sustaining occupational accidents. The investigation of accidents was carried out by Yazd Work Inspection Office. The total number of workers in this province was about 12000. The required data were collected on the basis of research purposes using a checklist. The list of variables in the study included date of accident, time of accident, work shift, age, occupation, working experience, educational level, insurance status, marital status, the consequence of the accident, the hurt organ, type of accident, and cause of accident. The data were analyzed using "Minitab" and descriptive statistics, Chi-square, Time Series, Trend analysis were used where appropriate. The Time Series Model was used in this study to estimate accidents among the Yazd construction workers up to 2011. The method of data fitting and curving, especially for annual data, was used to fit a simple function as the polynomial curve (linear, degree one, degree two ...) in the form of Gompers curve or logistic curve as the following:

Gompers curve: $I n x_{t}-u+b r^{*}$

Logistic curve: $x_{z}=a /[1+b \exp (-c t)]$

Obviously, when the time variable is large enough, these curves tend toward an asymptotic quantity. For both these curves, the fitted curve provides a measurement of the trend and the remainders offer the difference between observations and corresponding values of the fitted curve, providing an estimation of local fluctuations.

\section{Results}

A total of 247 construction workers suffering from injuries due to accidents in Yazd, Iran participated in this study. They belonged to the age group of 12-71 years with the mean age of 32. The accident rate was highest in the second half of the month specially the last 10 days of the month. About \% 45 of the accidents occurred in the last one-third (the last 10 days) of the month. The accidents mostly occurred in summer (\%31.58).

The rate of accidents increased throughout the 5 years during 2002-2006 with \%28.3 of the whole accidents occurring in 2005 . There was a little decrease in the rate in 2006. The amount of accidents occurring in the morning shift (\%72.87) was higher compared to the evening shift. Most of the injured workers (\%38.1) belonged to the age group of 20-29 and the least (\%21.5) belonged to the age group of 30-39. Most of the injured workers (\%33.20) had primary school education. Also, most of the injured workers (\%63.97) were married.

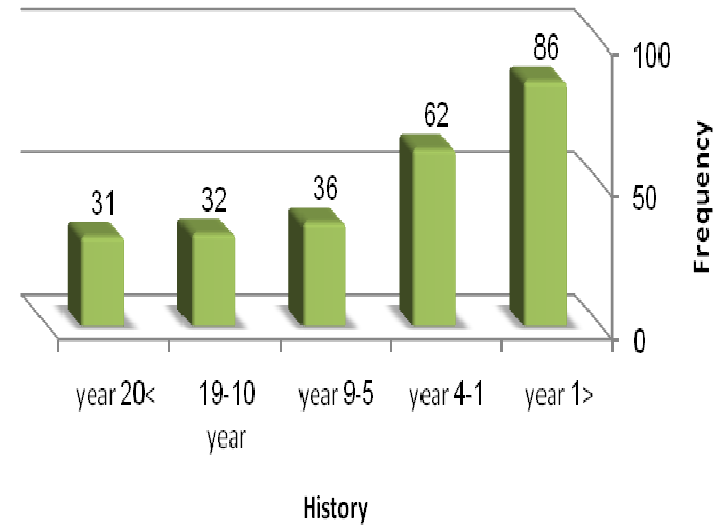

Figure 1.Frequency distribution of injured based on workers history $(n=247)$

Further, most of the accidents (\%46.6) occurred among the simple workers due to their nonstandard work, unsafe acts, and laborious task. Most of the injured workers (\%34.8) had less than one year working experience and \%13.4 of the injured workers had a working experience greater than 20 years. 
Table 1. Frequency distribution of injuired workers based on the type of job and their injured part of body.

\begin{tabular}{|c|c|c|c|c|c|c|}
\hline \multirow[b]{3}{*}{ job } & \multicolumn{6}{|c|}{ Injured part of body } \\
\hline & head & Hand and leg & $\begin{array}{c}\text { Back and } \\
\text { neck }\end{array}$ & $\begin{array}{l}\text { Heart and } \\
\text { lung }\end{array}$ & Other & total \\
\hline & $\begin{array}{c}\mathrm{N} \\
(\%)\end{array}$ & $\begin{array}{c}\mathrm{N} \\
(\%)\end{array}$ & $\begin{array}{c}\mathrm{N} \\
(\%)\end{array}$ & $\begin{array}{c}\mathrm{N} \\
(\%)\end{array}$ & $\begin{array}{c}\mathrm{N} \\
(\%)\end{array}$ & $\begin{array}{c}\mathrm{N} \\
(\%)\end{array}$ \\
\hline Simple worker & $\begin{array}{c}23 \\
(20)\end{array}$ & $\begin{array}{c}30 \\
(26.1)\end{array}$ & $\begin{array}{c}21 \\
(18.3)\end{array}$ & $\begin{array}{c}10 \\
(8.7)\end{array}$ & $\begin{array}{c}31 \\
(26.9)\end{array}$ & $\begin{array}{l}115 \\
100\end{array}$ \\
\hline Mason & $\begin{array}{c}10 \\
(21.3)\end{array}$ & $\begin{array}{c}11 \\
(23.4)\end{array}$ & $\begin{array}{c}12 \\
(25.5)\end{array}$ & $\begin{array}{c}10 \\
(21.3)\end{array}$ & $\begin{array}{c}4 \\
(8.5)\end{array}$ & $\begin{array}{c}47 \\
100\end{array}$ \\
\hline Well digger & $\begin{array}{c}1 \\
(8.3)\end{array}$ & $\begin{array}{c}0 \\
(0)\end{array}$ & $\begin{array}{c}4 \\
(33.3)\end{array}$ & $\begin{array}{c}1 \\
(8.3)\end{array}$ & $\begin{array}{c}6 \\
(50)\end{array}$ & $\begin{array}{c}12 \\
100\end{array}$ \\
\hline Driver and administrative & $\begin{array}{c}3 \\
(30)\end{array}$ & $\begin{array}{c}5 \\
(50)\end{array}$ & $\begin{array}{c}1 \\
(10)\end{array}$ & $\begin{array}{c}0 \\
(0)\end{array}$ & $\begin{array}{c}1 \\
(10)\end{array}$ & $\begin{array}{c}10 \\
100\end{array}$ \\
\hline Scaffolding Installers & $\begin{array}{c}3 \\
(21.4)\end{array}$ & $\begin{array}{c}4 \\
(28.6)\end{array}$ & $\begin{array}{c}5 \\
(35.7)\end{array}$ & $\begin{array}{c}0 \\
(0)\end{array}$ & $\begin{array}{c}2 \\
(14.2)\end{array}$ & $\begin{array}{c}14 \\
100\end{array}$ \\
\hline Welder and serviceman & $\begin{array}{c}1 \\
(12.5)\end{array}$ & $\begin{array}{c}2 \\
(25)\end{array}$ & $\begin{array}{c}2 \\
(25)\end{array}$ & $\begin{array}{c}1 \\
(12.5)\end{array}$ & $\begin{array}{c}2 \\
(25)\end{array}$ & $\begin{array}{c}8 \\
100\end{array}$ \\
\hline Other & $\begin{array}{c}4 \\
(9.8)\end{array}$ & $\begin{array}{l}16 \\
(39)\end{array}$ & $\begin{array}{c}10 \\
(24.4)\end{array}$ & $\begin{array}{c}4 \\
(9.7)\end{array}$ & $\begin{array}{c}7 \\
(17.1)\end{array}$ & $\begin{array}{c}41 \\
100\end{array}$ \\
\hline Total & $\begin{array}{c}45 \\
(100)\end{array}$ & $\begin{array}{c}68 \\
(100)\end{array}$ & $\begin{array}{c}55 \\
(100)\end{array}$ & $\begin{array}{c}26 \\
(100)\end{array}$ & $\begin{array}{c}53 \\
(100)\end{array}$ & $\begin{array}{c}247 \\
(100)\end{array}$ \\
\hline
\end{tabular}

Falling from a height" (\%48.6) was the most frequent cause of damage, while "damage due to suffocation" accounted for only $\% 2$ of the causes of accidents. In this study, \%55.9 of the accidents led to injury and fracture, $\% 25.1$ led to death, and \%19.03 led to crippling and invalidism. The correlation between the accident consequence and workers' age was not statistically significant $(\mathrm{P}=0.188)$. Most of the accidents leading to death (\%32.3), invalidism and disability (\%53.2), injury and fracture (\%35.5) belonged to the age group of 20-29. Although this correlation at the confidence level of $\mathrm{P}=0.05$ is not statistically significant, the $\mathrm{P}$-value shows that this finding may be generalized to $\% 81$ of the population. The correlation between accident consequence and workers' occupation was statistically significant $(\mathrm{P}<0.001)$ showing that most of the accidents leading to death occurred among simple workers (\%51.6). Also, injury, fracture, and invalidism occurred mostly among simple workers than other tasks (\%49.3 and \%31.9).

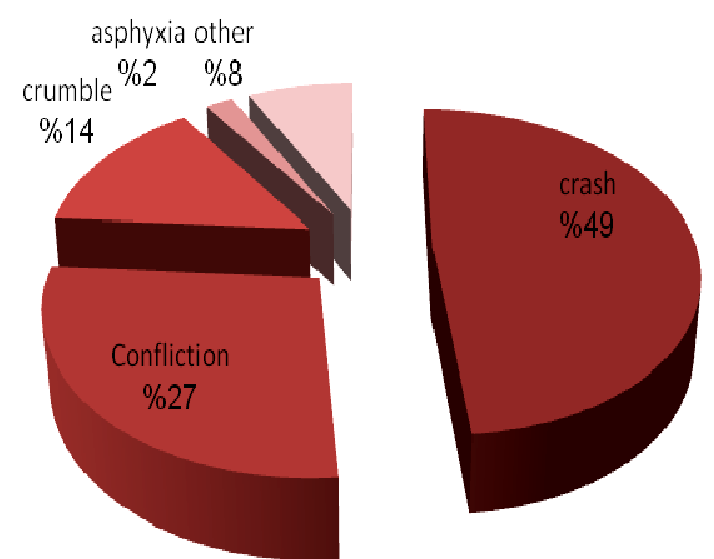

Figure2. Frequency distribution of injured workers based on type of accident $(n=247)$ 
Working experience showed no significant correlation with accident consequence $(\mathrm{P}=0.272)$. Most of the accidents leading to death, injury, fracture, and amputation occurred among the workers with a working experience of less than one year. Additionally, the correlation between education level and accident consequence was statistically significant $(\mathrm{P}<0.001)$. Most of the deaths (\%38.7) happened among the illiterate workers. Injury and fracture (\%36.9) mostly occurred among the workers with only primary education. Invalidism and amputation (\%36.2) mostly occurred among the workers with secondary education. There is no correlation between workers' marital status (single and married) and the consequences of accidents $(\mathrm{P}=0.41)$. Most cases of death, fracture, and amputation occurred among the married workers. There was a statistically significant correlation between workers' insurance status and accident consequence $(\mathrm{P}<0.001)$. In other words, death occurred mostly among the workers without any insurance (\%61.3). However, the rate of fractures and amputation was higher among the insured workers $(\% 62.3, \% 72.3)$. There was a statistically significant correlation between the injured part of body and accident consequence $(\mathrm{P}<0.0001)$. Damage to the head led to death in \%61.5 of the cases. Damage to the back and neck led to fracture and injury in $\% 34.8$ of cases. Also, damage to the arms and legs led to amputation of these parts and disability (\%57.45). No correlation was found between accident type and accident consequence in this study. After testing different models for accidents data, the second order model with the following equation matched our data:

$$
Y t=-6.6+30.7143 t-3.28571 t^{2}
$$

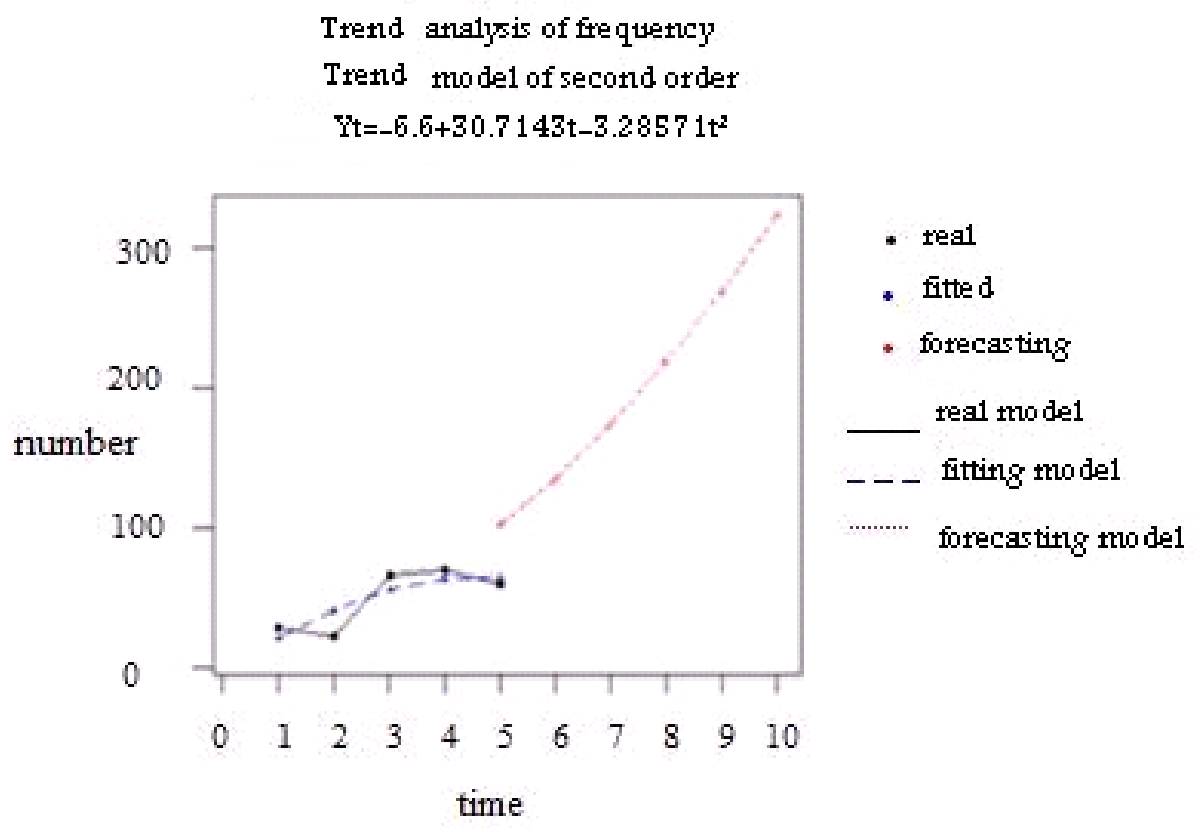

Figure3. Estimation model of accidents during 2006-2011 using the amount of accidents during 2001-2005.

As it is observed in figure 3 , in this model the dashed line indicates the fitting model and the continuous line indicates the real model which is extracted from our data. They are very close together and there is an approximation. Based on the presented 
model and using the fitting function values, this estimation can be used for predicting the rate of accidents during 2006-2011, which is much higher than those of real values and fitting function values and it can be hypothesized that in the case of the continuation of the current trend, the rate of accidents occurring in 2011 will exceed to 300 cases per year.

\section{DISCUSSION}

Insignificant accidents with minor injuries were excluded from the study. The population under study consisted of workers in the age group of 12-71 years old. This shows that teenagers without required professional skills and experience are also working in construction workshops due to the lack of supervision by the related legal organizations, leading to an increase in construction occupational accidents and casualties. The high rate of accidents in summer is due to the fact that the seasonal workers including high school and university students lacking the required professional skills and experience are put in to service. Also, due to appropriate climatic conditions in summer, construction workshops are much more active leading to an increase in the incidence of accidents. Furthermore, the higher rate of accidents during the morning hours is due to the higher intensity of work at this time as fewer workers are working in the afternoons and evenings.

The findings of the study indicate that about $\% 38$ of the injured subjects were between 20 and 29 , being consistent with findings by Jeong [14]. The results of the study also showed that mostly simple workers (\%46.6) followed by the expert builders (\%19.03) constituted the injured subjects. The high rate of accidents among the building workers could be due to their lack of enough working experience, and lack of training. The results of the study showed that the highest rate of accidents were among workers (\%34.8) with less than one year of working experience. Also, the lowest rate of accidents (\%12.5) belonged to workers with more than 20 years of working experience. This is consistent with Halvani et al's findings [11].

The findings of the study also revealed the point that "falling from a height" (\%48.6) formed the most frequent cause of damage. The statistics of American accidents in 2006 shows that $\% 20$ of accidents were due to falling from a height, being the highest rate. Also, \%21 of work accidents compensation belonged to this factor. Furthermore, the highest rate of accident consequences (\%87.5) belonged to injuries and fractures followed by the accidents leading to death (\%25.1). This shows that the severity and intensity of the injuries is induced by building accidents and is consistent with the findings by Colak, reporting the highest consequence rate of accidents as belonging to injuries and fractures (\%94.5) [12]. As it can be inferred from the findings of the study, the highest frequency of occurrences (\%48.6) belongs to carelessness and the lack of proper protective equipment or tools (\%28.7) and is rendered as the second leading cause of accidents, being consistent with the findings by Colak and Larsson $[12,15]$.

Regarding the results of the present study and other studies, the role of training in work safety principles and guidelines is accentuated. In other words, more than $\% 50$ of occupational accidents may be avoided via executing correct and efficient programs emphasizing the regulations of protective guidelines. On the whole, based on the results of this study and the estimation done on 300 accidents, it can be inferred that factors as teaching the safety principles to workers and obliging them to use some 
protective instruments, supervising the performance of young inexperienced workers, and emphasizing the observation of law, hygienic and protective principles, can greatly reduce the occurrence of accidents.

\section{Conclusion}

Regarding the estimation accidents rate during 2006-2011 in which the predicted values are much higher than the real and fitting function ones, compiling and provision of educational programs by communicative channels and mass media including radio, TV, local newspapers, and national journals and papers can encourage the use of safety tools and protective measures in the work environment especially the building construction activities.

\section{Acknowledgement:}

Authors are grateful to Dr. Abbas Bahrampour for his kind collaboration in this research.

Conflict of interest: Non declared

\section{References}

1. Choobineh AR Amirzadeh F (2003). General occupational health. $6^{\text {th }}$ edition. Shiraz, Publishers of Shiraz University of Medical Sciences 2003. [Persian]

2. Majori S, Bonizzato G, Signorelli D, Lacquaniti S, Andreeta L, Baldo V. Epidemiology and prevention of domestic injuries among children in the Verona area (north-east Italy). Ann Ig 2002; 14(6):495 502.

3. Al-Khatib A, Maqdadi R, Habash R, Aliyan G, Khofash F, Grayesh S. Work injuries in building construction, metal shaping, and food production sectors in Jericho District in the
Palestinian territory. East Mediterr Health J 2005; 11(5-6):1018-28.

4. Dong W, Vaughan P, Sullivan K, Fletcher T. Mortality study of construction workers in the UK. Int J Epidemiol 1995; 24(4):750-7.

5. Yu TS, Cheng FF, Tse SL, Wong TW. Assessing the provision of occupational health services in the construction industry in Hong Kong. Occup Med (Long) 2002; 52(7):375-82.

6. Wong TW. Occupational injuries among construction workers in Hong Kong. Occup Med (Long) 1994; 44(5):247-52.

7. Arndt V, Rothenbacher D, Daniel U, Zschenderlein B, Schuberth S, Brenner H. Allcause and cause specific mortality in a cohort of 20000 construction workers; results from a 10 year follow up. Occup Environ Med 2004; 61(5):419-25.

8. Arndt V, Rothenbacher D, Daniel U, Zschenderlein B, Schuberth S, Brenner $\mathrm{H}$. Construction work and risk of occupational disability: a ten year follow up of 14,474 male workers. Occup Environ Med 2005; 62(8):55966.

9. Mohammadfam I. Survey of work events and related factors in aluminum product factory of Iran in 1999. Kurdistan University of Medical Sciences, Scientific Magazine 2001; 19:18-32. [Persian]

10. Vazirinejad R. Survey of construction events in Rafsanjan City. Journal of Rafsanjan medical sciences; 4:326-31. [Persian]

11. Halvani Gh, Aminipoor MR. Survey of work events in factories of social securing organization in Yazd City. Toloe Behdasht Magazine 2004; 2:9-17. [Persian]

12. Colak B, Etiler N, Bicer U. Fatal occupational injuries in the construction sector in Kocaeli, Turkey, 1990-2001. Ind Health 2004; 42(4):424-30.

13. Chi CF, Chang TC, Hung KH. Significant industry-source of injuries-accident type for occupational fatalities in Taiwan. Int $\mathrm{J}$ Ind Ergon 2004; 34:77-91.

14. Jeong BY. Occupational deaths and injuries in the construction industry. Appl Ergon 1998; 29(5):355-60.

15. Larsson TJ, Field B. The distribution of occupational injuries risks in the victorian construction industry. Saf Sci 2002; 40:439-56.

16. Arboleda CA, Abraham DM. Fatalities in trenching operations - analysis using model of accident causation. Journal of Construction 
Engineering and Management 2004; 130: 27380.

17. Huang X, Hinze J. Analysis of construction worker fall accidents. Journal of Construction Engineering and Management 2003; 129:26271.

18. Hinze J, Huang $\mathrm{X}$, Terry L. The nature of struck-by accidents. Journal of Construction Engineering and Management 2005; 2:262-68.

19. Chi CF, Chang TC, Ting HI. Accident patterns and prevention measures for fatal occupational falls in the construction industry. Appl Ergon 2005; 36(4):391-400.

20. Sawacha E, Naoum S, Fong D. Factors affection safety performance on construction sites. International Journal of Project Management 1999; 17:309-15.

21. Rabi AZ, Jamous LW, Abu Dhaise BA, Alwash RH. Fatal occupational injuries in jordan during the period 1980 through 1993. Saf Sci 1998; 28:177-87.

22. Toole TM. Construction Site Safety Roles. Journal of Construction Engineering and Management 2002; 128:203-10.

23. Chia-Wen L, Yeng-Horng P. Data mining for occupational injuries in the Taiwan construction industry. Saf Sci 2007; 46:1091102. 